\title{
Effects of creative expression therapy on Chinese elderly patients with dementia: an exploratory randomized controlled trial
}

This article was published in the following Dove Press journal:

Neuropsychiatric Disease and Treatment

\author{
Rong Lin' \\ Hui-Ying Chen ${ }^{2}$ \\ Hong $\mathrm{Li}^{1,2}$ \\ Jing $\mathrm{Li}^{2}$
}

'Department of Nursing, Fujian Medical University, Fuzhou, People's Republic of China; ${ }^{2}$ Fujian Provincial Hospital,

Fuzhou, People's Republic of China
Correspondence: Hong Li

I34 East Street, Gulou District, Fuzhou City, Fujian Province, People's Republic of China

Tel +86I 3705070219

Fax +8659187532356

Email leehong99@126.com
Purpose: This study aimed to evaluate the effect of creative expression (CE) therapy on cognition, communication, emotion, and quality-of-life in people with dementia.

Methods: One hundred individuals were included in this study, of whom 91 completed the study (mean age $=84.33$ ). The participants were randomly assigned to an intervention group $(\mathrm{n}=43)$ and a control group $(\mathrm{n}=48)$, and received the CE program or standard cognitive (SC) training twice a week for 6 weeks, respectively. Both groups were submitted to extensive neuropsychological tests, as follows - Mini-Mental State Examination (MMSE), Quality of Life-Alzheimer's Disease (QOL-AD), Cornell Scale for Depression in Dementia (CSDD), Functional Assessment of Communication Skills (FACS) at baseline, 1-, and 4 -weeks postintervention, and the Observed Emotion Rating Scale (OERS) was measured during the intervention period at weeks 3 and 6 .

Results: The participants demonstrated significant improvements in cognitive function, quality-of-life, depression degree, communication ability, and emotion status $(P<0.05)$ at post-intervention, which were maintained at 1-month follow-up.

Conclusion: This study provides preliminary evidence that $\mathrm{CE}$ therapy developed in the study benefits elderly Chinese with dementia. The findings indicated that nonpharmacological intervention programs - CE therapy - can be applied in the management of neuropsychiatric symptoms of dementia.

Keywords: dementia, creative expression therapy, standard cognitive training, psycho-social intervention

\section{Introduction}

Dementia is a collective name for progressive degenerative neurocognitive disease, one of the greatest global challenge for health and social care in recent years. ${ }^{1}$ As the population ages, due to increasing life expectancy, the number of people with dementia is increasing rapidly, and is projected to treble to 131 million by $2050 .^{2}$ Dementia currently affects approximately 9.5 million Chinese people, accounting for $20 \%$ of the total number of world dementia patients, a figure expected to top 16 million by $2030 .^{2}$ Meeting the needs of very large numbers of people living with dementia and other age-related conditions is challenging for China.

The progressive condition of dementia affects older people by diminishing their memory, language, communication ability, mood, and personality. These losses not only impair a person's ability to function independently, but also have a negative impact on quality-of-life and relationships. ${ }^{3}$ Many people with dementia eventually 
become totally dependent on others. As a global health issue, dementia takes a heavy toll on people, society, and the economy. ${ }^{4}$ Researchers are exploring a range of promising findings related to the treatment of dementia. Damage to the brain can lead to dementia, therefore, limiting the extent and rate of progression of the pathological process producing this damage is a feasible approach.

Pharmacological therapies are effective, but have limitations to treat many symptoms caused by this progressive disease. However, a number of studies have pointed out that non-pharmacological treatments have significant advantages in clinically relevant outcomes. ${ }^{1,5,6}$ Among which cognitive stimulation therapy is an evidence-based psycho-social intervention ${ }^{7}$ that significantly demonstrates effects in treating neuropsychiatric symptoms and improving quality-of-life for persons with dementia, and one modality is creative expression (CE) programs, which engage people in supportive environments to produce something new that is of value to self and others. ${ }^{8}$

A particular CE program, called TimeSlips, from the Center on Age \& Community of Milwaukee at the University of Wisconsin is a non-pharmacological treatment that involves facilitators encouraging patients to exercise their creativity and imagination. ${ }^{8,9}$ Even people in the face of memory loss and disorientation could benefit from the activity. ${ }^{10}$ TimeSlips can prompt dementia patients with memory loss and hypo-function to express themselves, thus giving them social roles through imaginations to maintain their personhood. ${ }^{10}$ This process does not require dementia patients to have a good memory, and can be achieved through their existing functions.

There is a growing sense among healthcare providers that person-centered care (PCC) is a preferred choice for dementia care. ${ }^{11-13} \mathrm{PCC}$ is characterized by supporting the person's remaining abilities rather than their losses, and this process also includes meaningful social interactions and respect of personal preferences. ${ }^{13-15}$ The mode proposed by TimeSlips is highly conformed to PCC's principles. Kitwood ${ }^{16}$ developed a series of guiding PCC principles and asserted that good dementia care entails varied positive interactions in sequential processes, such as recognition, relaxation, play, creation, and so on. As a kind of group activity, the storytelling program may galvanize the spontaneity and inspiration of persons affected by dementia. During this group activity they can contact with others actively, thus satisfying their psychological needs and maintaining esteem. Therefore,
Timeslips has been recommended to be applied in persons with dementia. However, very little evidence is available on the response to treat neuropsychiatric symptoms and improve quality-of-life for people with dementia in China. Although some non-pharmacological therapies applied to Chinese people with dementia were reported, rarely have they been adequately evaluated, or systematically implemented. There were limited cross-cultural studies of behavioral and psychological therapy on people with dementia in China. Therefore, to address these gaps, we conducted an exploratory randomized controlled trial to examine the effects of short-term CE program in Chinese people with dementia.

\section{Participants and methods}

This study was designed as a prospective, non-blinded, randomized controlled trial to evaluate the feasibility and preliminary efficacy of the CE program in China. All participants volunteered to take part in the preliminary study, and they were fully informed about the content of study that includes the purpose, procedures, risks, and benefits of the research. As the participants were cognitively impaired, written consent was sought from their proxies. The Human Subjects Ethics Committee of Fujian Provincial Hospital approved the study (K2013010-01). The study was conducted according to the Declaration of Helsinki, ${ }^{17}$ and registered in the Chinese Clinical Trials Registry (trial registration number: ChiCTR-ONN-16007776).

\section{Setting}

In China, the Long-Term Care Facilities (LTCF) in the social service system are also known as residential care or nursing homes, where professional caregivers provide routine care for residents who need care, often with chronic diseases, disabilities, or cognitive impairment. ${ }^{18,19}$ This study was conducted at three nursing homes in Fuzhou, a city in southeastern China. During the study, an evaluation was implemented to ensure that the environment be bright and comfortable enough to make persons with dementia feel relaxed. ${ }^{20}$

\section{Participants}

A total of 100 persons with dementia from LTCF were invited to participate in the present study, and 91 finally completed the whole intervention. These participants were allocated randomly into two groups, which either received the CE program (intervention group, $n=43$ ) or standard 
cognitive (SC) training (control group, $\mathrm{n}=48$ ). Randomization was carried out by a statistician after screening was completed. Group assignment was concealed until the completion of baseline assessment. The assessor was not involved in the intervention, and the interventionists were not involved in the outcome assessments.

The recruitment of the participants is summarized in Figure 1. The inclusion criteria for participants were as follows: 1) aged $\geq 65$ years old; dementia diagnosis conformed to World Health Organization (WHO) and International Classification of Disease (ICD)-10; 2) MiniMental State Examination (MMSE) score of $\geq 11$ but $<27 ;^{21} 3$ ) understood and could speak Mandarin or Fuzhou dialects, with hearing adequate to hear the program dialog and eyesight adequate to observe the program stimulus picture. Patients with advanced terminal illness, learning disability, or those dropping out of the study without any follow-up were excluded.

\section{Sample size}

According to a previous study, ${ }^{22}$ we chose $\alpha=0.05$ and $\beta=0.10$. A16-sample pretest pilot was carried out to get $\delta=0.937$ and $\sigma=1.204$. It is estimated that the sample size in a single group could be 35 . In view of a $10 \%$ attrition rate, the sample size of two groups could reach 78 totally. The number of recruited participants $(n=91)$ is large enough in our study.

\section{Design}

Based on a community health action research model, participatory action research (PAR) was carried out to develop the feasible CE program in this study. Seven rounds of action research cycle, including plan, action, observation, and reflective discussion were completed. ${ }^{23}$ To prevent the Hawthorne effect of the intervention group, the participants in the control group received SC training. According to a related study, ${ }^{24}$ we designed the SC training as follows: orientation for time and place, songs in

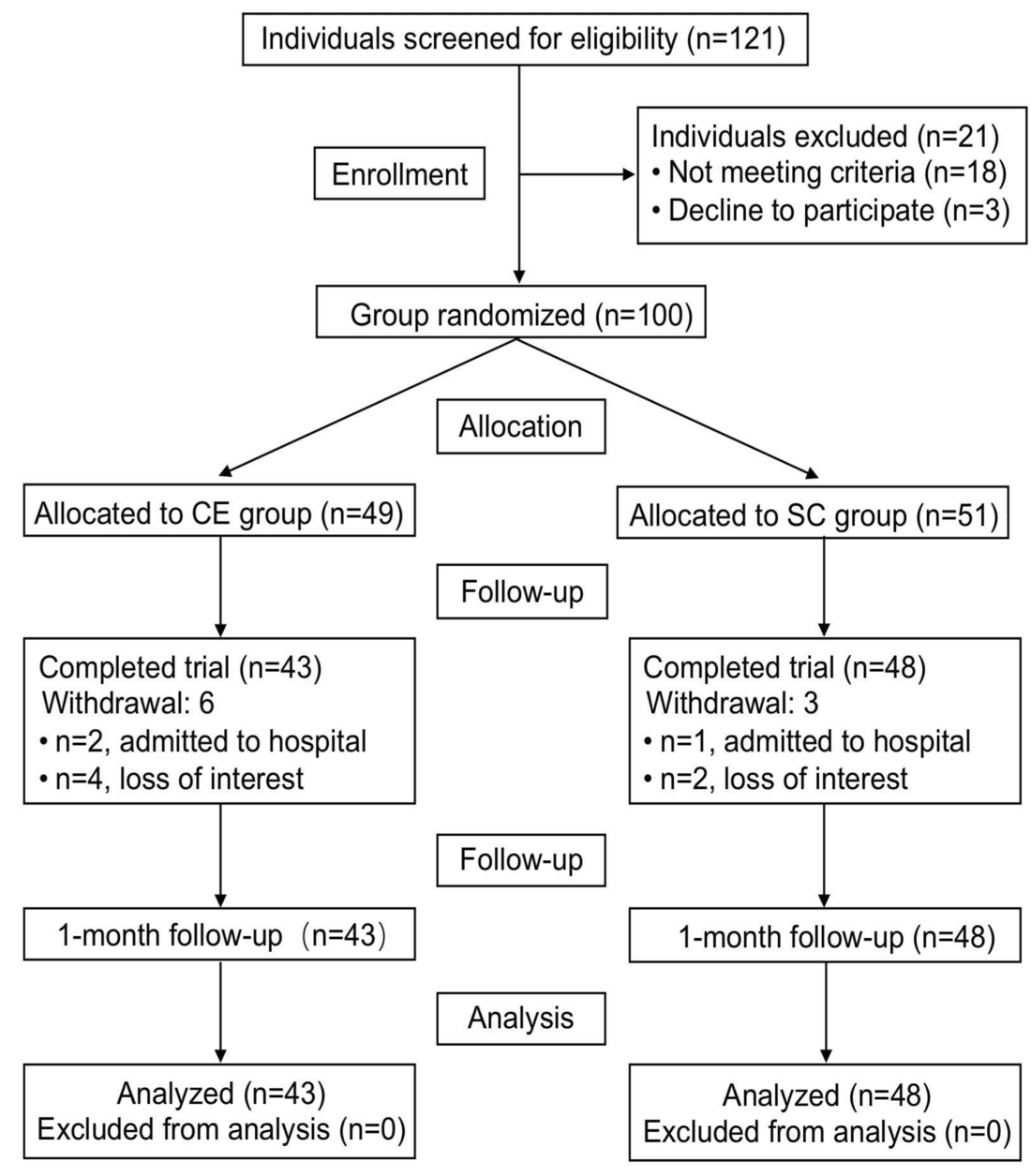

Figure I Study flow chart.

Abbreviations: CE, creative expression; SC, standard cognitive. 
chorus, recalling memorable events, appreciating music or documentaries, tangram puzzles, games (such as origami, maps, shovel beans, fishing), finger exercises or reading newspapers, event planning.

Participants in each group were divided into six subgroups with seven or eight persons with dementia. The activities were held twice a week, 1 hour each, for 6 weeks. After intervention, the ability of communication, cognition, mood, depression, and quality-of-life were evaluated post-intervention and 1-month following.

The programs in the two groups were carried out by a group of psychotherapists. Each session had one therapist to lead the delivery of the program, and two facilitators were responsible for observing and recording the responses of participants in activities. Meanwhile, a video recorder was used to record the details.

\section{Intervention}

\section{CE program}

An accredited therapist delivered the intervention twice a week for 6 weeks. The participants were encouraged to actively engage in the creative expression process and follow the therapist's instructions. The picture with a calming nature was selected, in accordance with participant preferences. Creative expression is characterized by active participation in the process of bringing something new into existence. In this study, "something new" included the creation of a story, perspective, or process, and the facilitator applied "openended" questions to encourage imagination and individual expression. There are five steps of functional tasks involved in this CE program, ie, the presentation of a picture, including the topic of the picture, the background scenery, the development of a story, the actions of the leading character, and the ending of the story. All sessions began with a 10 minute warm-up of an interaction game, followed by the 30 minute CE program, and then ended with a 5-10 minute discussion and a 5 minute conclusion. This activity combines with Kitwood's $^{16}$ theory of dementia care by promoting selfexpression and active interaction in a comfortable space, which give prominence to the uniqueness of persons, enabling them to feel concerned, supported, and cared for.

\section{SC training}

Participants in the control group received 6-week standard cognitive training (twice per week) facilitated by a group of occupational therapists (social workers, registered nurse, and physicians) Each session included 10 minutes of warm-up of an interaction game, followed by 30 minutes of core cognitive strategy training (a course, an activity, or a game) and, finally, 5-10 minutes of conclusion speeches. No specific creative activity was administered in the control group.

\section{Tools}

To compare the effect of CE storytelling on cognitive function, MMSE, Chinese version, were measured before and after intervention. MMSE consists of five items, including orientation, registration, attention, calculation, recall, and language and praxis. The Quality of Life-Alzheimer's Disease (QOL-AD) was designed specifically to obtain a rating of the quality-of-life of people with dementia. ${ }^{25}$ This brief and self-report questionnaire was designed, and a rating was obtained from both the participants and the caregiver. ${ }^{26}$ The depression degree of participants was measured by the Cornell Scale for Depression in Dementia (CSDD), ${ }^{27,28}$ including mood-related symptoms, behavioral disturbances, physical signs, cyclic functions, and ideational disturbances. The higher the score is, the more severe the depression is. The data was collected through interview or by formal caregivers of the people with dementia. Functional Assessment of Communication Skills (FACS) was used to measure participants' communication ability. FACS consists of four subscales: social communication (21 items), communication of basic needs (7 items), reading, writing, number concept (10 items), and daily planning (5 items). ${ }^{29}$ We have developed the Chinese version scale, authorized by the author in the preliminary study, which has revealed good reliability and validity in the Chinese population. ${ }^{30}$ The content validity index of this instrument was 0.91 ; internal validity was 0.93 ; test-re-test reliability was 0.839 ; and the inter-rater reliability was $0.61 .^{30}$ To figure out the emotion status in participants, the Observed Emotion Rating Scale (OERS) was measured during the intervention period, including five items: pleasure, anger, anxiety/fear, sadness, and general alertness. ${ }^{31}$ In the OERS, pleasure and general alertness belong to the positive emotions, while the remaining three are negative ones. ${ }^{32}$ Observation methods acquired first hand data by watching and inspecting an event or phenomenon. The observable phenomenon included personal characters and status, activity pattern, verbal and nonverbal communicating behavior, skill proficiency, environment feature, and so on. In this study, we applied structural standard observation to survey the mood of participants in CE storytelling environment with a duration of 10 minutes. 


\section{Statistical analysis}

Statistical analyses were carried out with IBM SPSS Statistics 21.0 The $P$-value was set to $P<0.05$. We used descriptive statistics-number (percentage) or mean \pm standard deviation (SD) to present the basic characteristics of the study participants. Group differences in demographics and baseline assessments were compared by using the appropriate statistical tests (independent samples $t$-test, or chi-square test). Analysis of variance (ANOVA) was used to compare the following three points: pre-intervention, post-intervention, and 1-month follow-up. A repeated measures analysis of covariance contained two factors, including group and time. The baseline of the outcome was used as the covariate. This method could compare changes of each dependent variable in the two groups, respectively, during different time periods. Observational data on staff-resident interactions and resident engagement were analyzed by independent samples $t$-test.

\section{Results}

\section{Participant characteristics}

Of the original 100 participants, nine dropped out shortly after the start of the study. Ninety-one participants from LTCF were recruited and allocated into two groups: CE $(n=43)$ and SC $(n=48)$. (Figure 1). No significant differences were observed between the control and intervention groups for all the baseline variables. The mean age of the participants was 84.33 ( $\mathrm{SD}=7.17)$, and the majority of them $(62.60 \%)$ were female. Most had received either secondary education or above (71.4\%). Demographic characteristics for each participant are presented in Table 1.

\section{Assessment of cognitive function, quality-of-life, depression, and communication ability}

All mean group assessment scores and between-group comparisons are illustrated in Table 2. The results of the

Table I Baseline demographic and neuropsychological evaluations of participants

\begin{tabular}{|c|c|c|c|c|}
\hline Characteristics & Overall $(n=91)$ & CE program $(n=43)$ & SC training $(n=48)$ & $P$-value \\
\hline Age, mean (SD) & $84.33(7.17)$ & $85.3(5.89)$ & $83.46(8.11)$ & $0.222^{\mathrm{a}}$ \\
\hline Gender (\%) & & & & $0.203^{\mathrm{b}}$ \\
\hline Male & $34(37.4)$ & $19(44.2)$ & $15(31.3)$ & \\
\hline Female & $57(62.6)$ & $24(55.8)$ & $33(68.8)$ & \\
\hline Marital status (\%) & & & & $0.43 \mathrm{I}^{\mathrm{b}}$ \\
\hline Married & $14(15.4)$ & $10(23.3)$ & $8(16.7)$ & \\
\hline Single/divorced & 77 (84.6) & $33(76.7)$ & $40(83.3)$ & \\
\hline Education level (\%) & & & & $0.288^{\mathrm{b}}$ \\
\hline No schooling/Primary & $26(28.6)$ & $10(23.3)$ & $16(33.3)$ & \\
\hline Secondary/Tertiary & $65(71.4)$ & $33(76.7)$ & $32(66.7)$ & \\
\hline Self-care (\%) & & & & $0.614^{\mathrm{b}}$ \\
\hline Fully self-care & $28(30.8)$ & $13(30.2)$ & $13(27.1)$ & \\
\hline Partially self-care & $53(58.2)$ & $22(5 \mid .2)$ & $29(60.4)$ & \\
\hline Totally incapacitated & $10(11.0)$ & $8(18.6)$ & $6(12.5)$ & \\
\hline MMSE score, mean (SD) & $18.55(4.97)$ & $18.72(4.85)$ & $18.40(5.13)$ & $0.758^{\mathrm{a}}$ \\
\hline QOL-AD scores, mean (SD) & $30.11(5.44)$ & $29.14(5.63)$ & $30.98(5.16)$ & $0.108^{\mathrm{a}}$ \\
\hline CSDD score, mean (SD) & $4.45(3.46)$ & $3.79(2.57)$ & $5.04(4.03)$ & $0.085^{\mathrm{a}}$ \\
\hline \multicolumn{5}{|l|}{ FACS score, mean (SD) } \\
\hline Social Communication & $5.85(0.90)$ & $5.88(0.96)$ & $5.83(0.85)$ & $0.802^{\mathrm{a}}$ \\
\hline Communication of Basic Needs & $6.04(1.08)$ & $5.82(1.10)$ & $6.23(1.05)$ & $0.073^{\mathrm{a}}$ \\
\hline
\end{tabular}

Notes: ${ }^{a}$ Independent sample $t$-test. ${ }^{\mathrm{b}} \mathrm{C}$ i-square test.

Abbreviations: MMSE, Mini-Mental State Examination; QOL-AD, Quality of Life-Alzheimer's Disease; CSDD, Cornell Scale for Depression in Dementia; FACS, Functional Assessment of Communication Skills; CE, creative expression; SC, standard cognitive. 


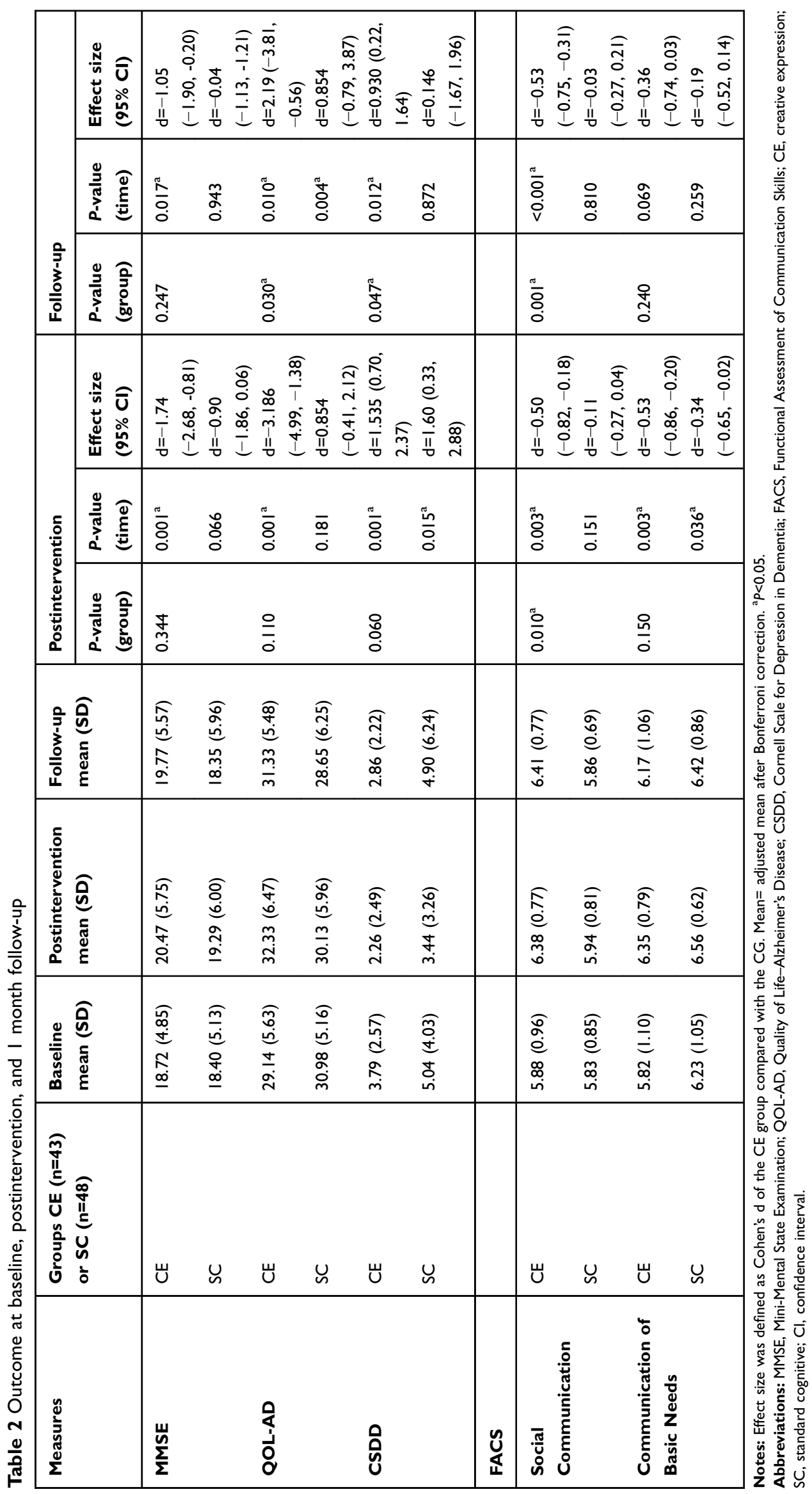


repeated-measures ANOVA showed significant improvements in the CE group in all measurements at post-intervention and at 1 month follow-up. Similarly, there was significant improvement in all assessments in the SC, except cognitive function (MMSE) and quality-of-life (QOL-AD). At post-intervention, there were no significant differences observed between the $\mathrm{CE}$ and SC groups. At 1 month follow-up, the $\mathrm{CE}$ group showed significantly greater improvement than the SC group in quality-of-life (QOL-AD, $P<0.05$ ), depression (CSDD, $P<0.05$ ), and social communication (FACS, $P<0.001$ ).

\section{Observation of emotions during the intervention}

The OERS uses five domains to assess the emotional state of participants, namely pleasure, general alertness, anger, anxiety or fear, and sadness (Table 3). As shown in Table 3, OERS scores in participants of the two groups were compared at weeks 3 and 6 . The results showed that pleasure scores and general alertness scores in OERS scale in the $\mathrm{CE}$ group were significantly higher than that in control group ( $P=0.006$, week $3 ; P=0.007$, week 6$)$. The scores for the other domains did not differ significantly. During the activity, anger, anxiety, fear, or sadness were rarely observed in participants of the CE group.

\section{Discussion}

The aim of this study was to investigate the advantages of the short-term CE program for people with dementia living in long-term care facilities. As this was an exploratory study, designed with the goal of providing preliminary data regarding treatment effect that would indicate whether longitudinal follow-up was warranted, a relatively brief followup interval of 1 and 4 weeks post-intervention was used. The 6-week intervention program led to a significant difference between the experimental and comparison groups in the quality-of-life, depression, and social communication scores at 1 month follow-up. The participants in the CE group showed greater improvement in cognitive function, qualityof-life, depression, and communication ability at post-intervention and at 1 month follow-up. Furthermore, the results observed during the intervention showed that the CE group had a better emotional state than the control group.

People with dementia are a vulnerable group, so all participants need to be treated equally and their privacy should be respected in our study, and we do our best not to put them at any risk. Although participants are cognitively compromised, and written consent was provided by their proxies, but informed consent is an expression of their true opinion. Moreover, during the TimeSlips sessions, stressfree relaxing and comfortable environment are essential to enhance participants' sense so that they can exploit creative potentials, retain strengths, and experience the feeling of respect and acceptance. Also, if participants have any negative emotions, they should be comforted promptly during the activity.

During the whole process of TimeSlips activities, participants were encouraged to express creatively, and their language skills were promoted despite the change not being significant. A study demonstrated that around $10 \%$ of participants could be treated completely, even when diagnosed in an early stage. ${ }^{33}$ Although non-drug therapy methods may not completely cure dementia, they may

Table 3 The result of OERS

\begin{tabular}{|c|c|c|c|c|c|c|c|c|}
\hline \multicolumn{2}{|l|}{ Measures } & \multirow{2}{*}{$\begin{array}{l}\text { Group CE }(n=43) \text { or } \\
\text { SC }(n=48)\end{array}$} & \multicolumn{3}{|l|}{ Week 3} & \multicolumn{3}{|l|}{ Week 6} \\
\hline & & & Mean (SD) & $95 \% \mathrm{Cl}$ & $P$ & Mean (SD) & $95 \% \mathrm{Cl}$ & $P$ \\
\hline $\begin{array}{l}\text { Positive } \\
\text { emotions }\end{array}$ & $\begin{array}{l}\text { Pleasure } \\
\text { General } \\
\text { alertness }\end{array}$ & $\begin{array}{l}\text { CE } \\
\text { SC } \\
\text { CE } \\
\text { SC }\end{array}$ & $\begin{array}{l}3.23(1.65) \\
2.21(1.77) \\
5.00(0.00) \\
4.46(1.34)\end{array}$ & $\begin{array}{l}0.309-1.740 \\
0.154-0.930\end{array}$ & $\begin{array}{l}0.006^{\mathrm{a}} \\
0.007^{\mathrm{a}}\end{array}$ & $\begin{array}{l}3.77(1.445) \\
2.85(2.000) \\
4.95(0.21) \\
4.63(0.76)\end{array}$ & $\begin{array}{l}0.191-1.635 \\
0.099-0.558\end{array}$ & $\begin{array}{l}0.014^{\mathrm{a}} \\
0.006^{\mathrm{a}}\end{array}$ \\
\hline $\begin{array}{l}\text { Negative } \\
\text { emotions }\end{array}$ & $\begin{array}{l}\text { Anger } \\
\text { Anxietyl } \\
\text { Fear } \\
\text { Sadness }\end{array}$ & $\begin{array}{l}\text { CE } \\
\text { SC } \\
\text { CE } \\
\text { SC } \\
\text { CE } \\
\text { SC }\end{array}$ & $\begin{array}{l}\text { I.07 (0.46) } \\
\text { I.04 (0.29) } \\
\text { I.00(0.00) } \\
\text { I.04 (0.20) } \\
\text { I.00(0.00) } \\
\text { I.06(0.43) }\end{array}$ & $\begin{array}{l}-0.130-0.186 \\
-0.100-0.017 \\
-0.194-0.069\end{array}$ & $\begin{array}{l}0.724 \\
0.159 \\
0.347\end{array}$ & $\begin{array}{l}\text { I.00 (0.00) } \\
\text { I.06(0.25) } \\
\text { I.02(0.15) } \\
\text { I.00(0.00) } \\
\text { I.02(0.15) } \\
\text { I.02(0.14) }\end{array}$ & $\begin{array}{l}-0.134-0.009 \\
-0.024-0.070 \\
-0.059-0.064\end{array}$ & $\begin{array}{l}0.083 \\
0.323 \\
0.938\end{array}$ \\
\hline
\end{tabular}

Notes: $P$-value by independent $t$-test. ${ }^{\mathrm{a}} \mathrm{P}<0.05$.

Abbreviations: OERS, Observed Emotion Rating Scale; CE, creative expression; SC, standard cognitive; Cl, confidence interval. 
delay late severe symptoms. CE intervention may benefit the persons with mild-to-moderate dementia. In addition, our results demonstrated that the $\mathrm{CE}$ intervention could significantly improve the quality-of-life in people with dementia.

In recent years, studies of depression on the prognosis of dementia have expanded rapidly. Contrasted with healthy elders, people with dementia have a higher incidence of depression, accounting for about $80 \%$ of total dementia patients. ${ }^{34}$ Evidence illustrates that depression will not only delay the recovery of nerve function defects or cognitive impairment, but increase the mortality of cerebrovascular disease, and reduce the quality-of-life. ${ }^{35,36}$ In this study, it appeared that both interventions may have a remission effect on depression, but the intervention group had an improved maintenance efficacy. CE therapy can significantly improve the depressive symptoms of people with mild-to-moderate dementia. As described in a previous study, participating in an activity was an important factor to decrease depression. ${ }^{37-39} \mathrm{CE}$ therapy gave the participants a new social role of self-value and alleviated depression symptoms.

Both "social communication" and "communication of basic needs" were affected significantly by TimeSlips. During CE therapy, participants were encouraged to tell stories, which trained their communication ability. When participants' communication skills improve, they express their needs clearly, thus the burden on caregivers may be reduced as well. Meanwhile, the participants receiving CE therapy had higher scores in the intervention group than the control group.

Like general social attention, CE therapy can also affect the main emotional performance, happiness, and alertness of people with dementia. The CE therapy makes participants more confident and feel affirmed. Participants' negative mood may disappear gradually, and be replaced by happy and alert moods. Our results suggested that paying more attention to persons with dementia contributes to positive emotions. A randomized, controlled trial among 28 elderly patients with dementia demonstrated that $\mathrm{CE}$ therapy had a positive effect on patients with Alzheimer's mood, communication ability, and depression symptoms. ${ }^{40}$ However, the results did not reach the statistically significant level. Some studies indicated that participants in the test group receiving CE therapy once a week for 10 weeks were more active, positive, and communicative than those in the control group receiving routine nursing intervention. ${ }^{10,41}$ In Bahlke et al's ${ }^{42}$ study, seven patients with moderate-to-severe dementia received CE therapy, and results proved that creative storytelling benefited dementia patients' oral communication, social interaction, and emotional state. However, none of these researchers considered the social attention bias in the control group except our study. In addition, compared with the studies above, the sample size of 91 in our study is larger. This study demonstrated that CE therapy greatly contributed to elderly people with dementia.

\section{Limitations and future research}

There were several limitations in this study. In China, health service resources are too limited to meet the healthcare need, and the number of people with dementia increases annually. Due to the time and resource limits, the eligible subjects in the study were only selected from Fuzhou city. In addition, participating nursing homes with dementia wards are scarce in Fuzhou city. It was challenging to conduct a cohort and multicenter study with such a large sample size. Second, considering that the participants need to have a certain level of ability to understand and communicate, only participants with mild and moderate dementia were recruited, while those with advanced dementia weren't. Third, the delivery of intervention endured for a period of only 10 weeks, and the findings may be limited and the effective initiating time cannot be determined. Future studies might prolong the intervention to explore the preferable intervention cycle and frequency of CE therapy. Although the findings are positive and certainly interesting, future research should focus on assessing not only neuropsychological outcome measures, but also imaging features, so as to explore the intervention mechanisms. Researchers could also try to compare CE therapy with other psychosocial interventions (such as music therapy) or pharmacotherapies. In this study, the providers of CE therapy are psychotherapists. The next step could be to train the nurses or caregivers to become the implementer and provide CE therapy in the daily care of dementia.

\section{Conclusion}

The CE intervention developed in our study greatly contributed to elderly people with dementia. It is feasible to apply CE intervention in the management of dementia treatment. Our findings provided a trans-cultural evidence on dementia treatment.

\section{Acknowledgments}

The authors appreciate Dr. Gordon Taylor, and Professors Dr. David Wainwright, and Dr. Alan Buckingham for their 
advice. This work was supported by a grant from the National Natural Science Foundation of China (grant number 81571379), Startup Fund for Scientific Research, Fujian Medical University, China (grant number: 2018QH2023), and Leading Project of Fujian Province, China (grant number: 2017Y0013); and had no role in the study design, data collection, analysis, decision to publish, or manuscript preparation.

\section{Disclosure}

Rong Lin and Hui-Ying Chen are co-first authors. The authors report no conflicts of interest in this work.

\section{References}

1. Livingston G, Sommerlad A, Orgeta V, et al. Dementia prevention, intervention, and care. Lancet. 2017;390(10113):2673-2734. doi:10.1016/S0140-6736(17)31363-6

2. Price M, Herrera A, Knapp M, et al. World Alzherimer Report: Improving Healthcare for People Living with Dementia: Coverage, Quality and Costs Now and in the Future. Alzheimer's Disease International. London; 2016.

3. Hsu TJ, Tsai HT, Hwang AC, Chen LY, Chen LK. Predictors of non-pharmacological intervention effect on cognitive function and behavioral and psychological symptoms of older people with dementia Geriatr Gerontol Int. 2017;17(S1):28-35. doi:10.1111/ggi.13037

4. Pin S, Spini D. Meeting the needs of the growing very old population: policy implications for a global challenge. Aging Soc Policy. 2016;28(3):218-231. doi:10.1080/08959420.2016.1181972

5. Brown CA, Berry R, Tan MC, Khoshia A, Turlapati L, Swedlove F. A critique of the evidence base for non-pharmacological sleep interventions for persons with dementia. Dementia. 2013;12(2):210-237. doi:10.1177/1471301211426909

6. Huntley JD, Gould RL, Liu K, Smith M, Howard RJ. Do cognitive interventions improve general cognition in dementia? A meta-analysis and meta-regression. BMJ Open. 2015;5(4):e005247. doi:10.1136/bmjopen-2014-005247

7. Ali A, Brown E, Spector A, Aguirre E, Hassiotis A. Individual cognitive stimulation therapy for people with intellectual disability and dementia: protocol of a feasibility randomised controlled trial. BMJ Open. 2018;8(12):e22136. doi:10.1136/bmjopen-2018022136

8. Fritsch T, Kwak J, Grant S, Josh L, Montgomery RR, Basting AD. Impact of TimeSlips, a creative expression intervention program, on nursing home residents with dementia and their caregivers. Gerontologist. 2009;49(1):117-127. doi:10.1093/geront/gnp008

9. Zhao J, Li H, Lin R, Wei Y, Yang A. Effects of creative expression therapy for older adults with mild cognitive impairment at risk of Alzheimer's disease: a randomized controlled clinical trial. Clin Interv Aging. 2018;13:1313-1320. doi:10.2147/CIA.S161861

10. Houser WS, George DR, Chinchilli VM. Impact of TimeSlips creative expression program on behavioral symptoms and psychotropic medication use in persons with dementia in long-term care: a cluster-randomized pilot study. Am J Geriatr Psychiatry. 2014;22 (4):337-340. doi:10.1016/j.jagp.2012.12.005

11. Organization WH. Towards a dementia plan: a WHO guide. 2018; Available from: http://www.who.int/iris/handle/10665/272642. Accessed December 26, 2018. License: CC BY-NC-SA 3.0 IGO.

12. Edvardsson D, Winblad B, Sandman PO. Person-centred care of people with severe Alzheimer's disease: current status and ways forward. Lancet Neurol. 2008;7(4):362-367. doi:10.1016/S1474-4422(08)70063-2
13. McCormack B, McCance T. Person-Centred Nursing: Theory and Practice. Chichester: John Wiley \& Sons; 2011.

14. Kitson A, Marshall A, Bassett K, Zeitz K. What are the core elements of patient-centred care? A narrative review and synthesis of the literature from health policy, medicine and nursing. J Adv Nurs. 2013;69(1):4-15. doi:10.1111/j.1365-2648.2012.06064.x

15. Kogan AC, Wilber K, Mosqueda L. Person-centered care for older adults with chronic conditions and functional impairment: a systematic literature review. J Am Geriatr Soc. 2016;64(1):e1-e7. doi:10.1111/ jgs. 13873

16. Kitwood TM. Dementia Reconsidered: The Person Comes First. Buckingham: Open university press; 1997.

17. World Medical Association Declaration of Helsinki: ethical principles for medical research involving human subjects. Jama. 2013;310 (20):2191-2194. doi:10.1001/jama.2013.281053

18. Scott V, Votova K, Scanlan A, Close J. Multifactorial and functional mobility assessment tools for fall risk among older adults in community, home-support, long-term and acute care settings. Age Ageing. 2007;36(2):130-139. doi:10.1093/ageing/afl165

19. Zhang L, Zeng Y, Weng C, Yan J, Fang Y. Epidemiological characteristics and factors influencing falls among elderly adults in long-term care facilities in Xiamen, China. Medicine. 2019;98(8): e14375. doi:10.1097/MD.0000000000014375

20. Li H, Ke SF, Zheng JH, et al. The status of therapeutic environment for dementia pafients in long-term care facilities in Fujian province. Chin J Nurs. 2014;5:526-531.

21. Folstein MF, Folstein SE, McHugh PR. "Mini-mental state". A practical method for grading the cognitive state of patients for the clinician. J Psychiatr Res. 1975;12(3):189-198. doi:10.1016/ 0022-3956(75)90026-6

22. Kim HY. Statistical notes for clinical researchers: sample size calculation 2. Comparison of two independent proportions. Restor Dent Endod. 2016;41(2):154-156. doi:10.5395/ rde.2016.41.2.154

23. Li J, Chen P, Wei YP, Chen HY, Hong LI. Application research of Chinese creative storytelling project for patients with senile dementia. Chin J Nurs. 2015;50(12):1463-1466.

24. Vilela VC, Pacheco RL, Latorraca COC, Pachito DV, Riera R. What do Cochrane systematic reviews say about non-pharmacological interventions for treating cognitive decline and dementia? Sao Paulo Med J. 2017;135(3):309-320. doi:10.1590/15163180.2017.0092060617

25. Logsdon RG, Gibbons LE, Mccurry SM, Teri L. Assessing quality of life in older adults with cognitive impairment. Psychosom Med. 2002;64(3):510-519.

26. Kang Y, Lee E. Quality of life and its factors in korean elderly with mild cognitive impairment. Clin Nurs Res. 2018;27(7):871-889. doi:10.1177/1054773817714561

27. Alexopoulos GS, Abrams RC, Young RC, Shamoian CA. Cornell scale for depression in dementia. Biol Psychiatry. 1988;23(3):271-284.

28. Jeon YH, Liu Z, Li Z, et al. Development and validation of a short version of the cornell scale for depression in dementia for screening residents in nursing homes. Am J Geriatr Psychiatry. 2016;24 (11):1007-1016. doi:10.1016/j.jagp.2016.05.012

29. Austin S. American Speech-Language-Hearing Association Functional Assessment of Communication Skills. New York: Springer; 2013.

30. Chen H. Effects of Timeslips Intervention on Quality of Life in Elderly Patients with Dementia. Fuzhou, Fujian Medical University; 2015.

31. Lawton M, Van Haitsma K, Perkinson M, et al. Observed affect and quality of life in dementia: further affirmations and problems. Ment Health Aging. 1999;5:69-82.

32. Innes A, Kelly F, Scerri C, Abela S. Living with dementia in hospital wards: a comparative study of staff perceptions of practice and observed patient experience. Int J Older People Nurs. 2016;11 (2):94-106. doi:10.1111/opn.12102 
33. Meyer G, Stephan A, Renom-Guiteras A, et al. Caring for a person with dementia on the margins of long-term care: a perspective on burden from 8 European countries. J Am Med Dir Assoc. 2017;18 (11):967-973. doi:10.1016/j.jamda.2017.06.004

34. Fulvia DI, Katie P, Carlo B, et al. Occurrence of neuropsychiatric symptoms and psychiatric disorders in mild Alzheimer's disease and mild cognitive impairment subtypes. Int Psychogeriatr. 2010;22 (4):629-640. doi:10.1017/S1041610210000281

35. Gutzmann H, Qazi A. Depression associated with dementia. Z Gerontol Geriatr. 2015;48(4):305-311. doi:10.1007/s00391-0150898-8

36. Tay KW, Subramaniam P, Oei TP. Cognitive behavioural therapy can be effective in treating anxiety and depression in persons with dementia: a systematic review. Psychogeriatrics. 2019;19(3):264275 .

37. Marheineke J, Deck R, Reuther P, Poppl D, Theves F, Kohlmann T. Participation after stroke: the influence of depression in outpatient neurological rehabilitation. Nervenarzt. 2019;90 (40):352-360.
38. Kang H. Correlates of social engagement in nursing home residents with dementia. Asian Nurs Res (Korean Soc Nurs Sci). 2012;6 (2):75-81. doi:10.1016/j.anr.2012.05.006

39. Ishikawa M, Tamakoshi $\mathrm{K}$, Yatsuya $\mathrm{H}$, et al. Factors related to frequency of engaging in outside activities among elderly persons living an independent life at home. Nagoya J Med Sci. 2006;68 (3-4):121-130.

40. Phillips LJ, Reid-Arndt SA, Pak Y. Effects of a creative expression intervention on emotions, communication, and quality of life in persons with dementia. Nurs Res. 2010;59(6):417-425. doi:10.1097/ NNR.0b013e3181faff52

41. George DR, Houser WS. "I'm a storyteller!": exploring the benefits of TimeSlips creative expression program at a nursing home. $\mathrm{Am}$ J Alzheimer Dis Other Dementias. 2014;29(8):678-684. doi:10.1177/ 1533317514539725

42. Bahlke L, Pericolosi S, Lehman ME. Use of timeslips to improve communication in persons with moderate-late stage dementia. $J$ Aging Humanities Arts. 2010;4(4):390-405. doi:10.1080/ 19325614.2010.535239

\section{Publish your work in this journal}

Neuropsychiatric Disease and Treatment is an international, peerreviewed journal of clinical therapeutics and pharmacology focusing on concise rapid reporting of clinical or pre-clinical studies on a range of neuropsychiatric and neurological disorders. This journal is indexed on PubMed Central, the 'PsycINFO' database and CAS, and is the official journal of The International Neuropsychiatric Association (INA). The manuscript management system is completely online and includes a very quick and fair peer-review system, which is all easy to use. Visit http://www.dovepress.com/testimonials.php to read real quotes from published authors. 